Leo Spitzer, NRFH, IV, I950, págs. 50-56, ha propuesto leer las I 3 estrofas de esta cántica en otro orden que el tradicional, y ha sustentado agudamente sus proposiciones teniendo "en cuenta la técnica verbal de Berceo, quien, como buen predicador medieval, procede por repeticiones martillantes de palabras y de motivos, por enumeraciones y recapitulaciones, por bloques sucesivos de variantes, es decir, por medios intelectuales destinados en nuestro caso a balancear el efecto músicoemocional del estribillo jeya velar!'”. En suma, Spitzer ha procedido por consideraciones estilísticas y de historia cultural. Aunque en proporciones mucho más moderadas, ya han sido varios los intentos de reordenación de esas estrofas que se han hecho en lo que va de siglo, y las razones tenidas en cuenta, aunque muy lejos de la elaboración exhaustiva de Spitzer, son del mismo género que las suyas. Sólo que donde Spitzer, el medievalista nivelador, busca lo típico "medieval", los otros han visto el sello de procedimientos poéticos peninsulares.

Garolina Michä̈lis de Vasconcelos, Cancionero de Ajuda, I 904, II, pág. 929, n., al hablar de los procedimientos paralelísticos de la poesía gallego-portuguesa, anota: "Tiene su lugar aquí (en nota por lo menos) una referencia al Cantar de los Judíos intercalado por Gonzalo de Berceo en el Duelo de la Virgen (estr. I78-19I) y considerado por la crítica como fragmento de una representación pascual. En sus trece dísticos, acompañados del refrán eya velar, que es, como he mostrado, típico de los Cantos de romerías, hay por ventura restos de versiones imperfectamente paralelas. Distingo cuatro grupos, formados por las estrofas I8o, 185, I 86 (á-o); I81 y I83 (é-o); 182 y I 84 (é-a); I 87 y I $89(e ́-o)^{\prime \prime}$. O sea, contando las estrofas de I a I3; I, 3, 8 y 9 ; II, 4 y 6 ; III, 5 y 7 ; IV, Io y I 2. Nada dice doña Carolina de las estro- . fas I, 2, I I, y I3, ni se cuida del orden que cada estrofa debe llevar dentro de su grupo ni los grupos entre sí: ella no aduce el eya velar más que por sus paralelismos. En la más elaborada ordenación de Leo Spitzer los grupos de doña Carolina se disponen así: IV, II, III, I; en el I y en el III está invertido también el orden de las estrofas (9-8-3, en vez de 3-8-9, y 7-5 en vez de 5-7, aunque del examen de estas dos estrofas Spitzer admite la posibilidad del orden 5-7).

Manuel Rodrigues Lapa, Das origens da poesía lírica em Portugal na Idade Media, I929, va también al estudio del eya velar atraído por sus paralelismos. Primero, págs. 274, 288, encuentra los juegos paralelísticos en todo el Duelo de la Virgen como elementos de composición literaria, y hasta esboza una excelente clasificación de los procedi-

"used by keepers of old in derision of their victims". L. SpItzer, Neuphilol. Mitteil., XV, pág. I72, n. 2, menciona el catalán perder l'oremus 'perder la razón' y lo combina con la locución latina, lo que, por confusión, llevó a Meyer-Lübke a registrar orate también bajo orare, olvidándose de lo que él mismo había sostenido en el artículo núm. 788. Sin embargo, no es improbable que la locución perder l'oremus haya tomado este sentido por alguna vaga influencia de orat. 
mientos ${ }^{1}$. Y en otro lugar, págs. 345-46, después de observar cómo los trovadores galaico-portugueses tomaban con frecuencia de la poesía tradicional frases ya elaboradas paralelísticamente, destacando que los primeros esbozos populares solían desarrollar el paralelismo en parejas, prosigue: "En [el eya velar de] Berceo aparece justamente ese sistema: el primer verso del dístico es el que determina, más bien que el segundo, el encadenamiento, la relación de sentido; y la unidad paralelística está constituída por dos estrofas". Y en nota: "Cf. Duelo de la Virgen, 709 sigs. (léase I 79 sigs.), modificando un poco el orden de los versos que parece no estar bien", y aquí pone en parejas las estrofas 4-6, 5-7, 8-9. La última pareja, ya lo venimos viendo, es en realidad un trío, 3-8-9, del que Rodrigues Lapa ha callado la primera estrofa en servicio de su idea del paralelismo dual. Reponiéndola en su lugar y prescindiendo de las no atendidas por el autor, obtenemos el orden señalado en el cuadro.

Por último F. Brittain, The medieval Latin and Romance lyric to A. D. I 300 , Cambridge, I937, pág. 37, tras llamar la atención sobre el eya velar "con sus repeticiones y su estribillo en estilo semipopular", luego dice en la Antología, págs. I 82-83: "Hay mucha repetición y paralelismo en sus estrofas, que arreglo en el orden sugerido por el señor Rodrigues Lapa". Y lo hace como lo indicamos en el cuadro.

$\begin{array}{lrrrrrrrrrrrrr}\text { Tradicional } & \text { I } & 2 & 3 & 4 & 5 & 6 & 7 & 8 & 9 & \text { I0 } & \text { I I } & \text { I2 } & \text { I3 } \\ \text { Michaelis } & & & 3 & 8 & 9 & 4 & 6 & 5 & 7 & \text { IO } & \text { I 2 } & & \\ \text { R. Lapa } & & & 4 & 6 & 5 & 7 & 3 & 8 & 9 & & & \\ \text { Brittain } & \text { I } & 2 & 4 & 6 & 5 & 7 & 3 & 8 & 9 & \text { I I } & \text { I0 } & \text { I2 } & \text { I3 } \\ \text { Spitzer } & \text { I } & 2 & \text { IO } & \text { I } 2 & 4 & 6 & \text { I3 } & \text { I I } & 7 & 5 & 9 & 8 & 3\end{array}$

Los cuatro coinciden en que el orden de las estrofas recibido tiene que estar viciado, y su coincidencia hace más confiada nuestra aceptación. En cuanto a la ordenación que hemos de preferir como la más probable, eso depende de las atribuciones que la crítica filológica conceda al reordenador. Doña Carolina y Rodrigues Lapa ciertamente no han hecho más que juntar los miembros paralelísticos que aparecían dispersos o interpolados, y consecuentemente Fred Brittain, que los sigue, ha introducido en el orden general de las estrofas la variación mínima y necesaria para obtener, a la vez que la restauración de los dañados paralelismos, una secuencia satisfactoria de sentido. Lo demás queda como estaba, ya que no ven motivo especial para negar su autenticidad. Spitzer en cambio entiende que, pues algo está de seguro desordenado, todo lo

1 Son tres: un verso repetido con variante sinonímica al fin ("Ruégote que $\mathrm{m}$ ' condones esto que yo te digo, / Ruégote que $\mathrm{m}$ ' condones esto que yo te pido"), repetido con trasposición de sus elementos ("Faciéndoli bocines judíos e paganos, / Judíos e paganos faciéndoli bocines"), o repetido sólo en cuanto al sentido ("Ome de la su boca nunca fué denostado. / Non fué de la su gracia ninguno repoiado. / Nunca repoyó ome justo nin pecador"). 
puede estar. Lo cual si es difícil de aceptar en cuanto a la totalidad, es en cambio irreprochable en cuanto a cada estrofa en particular. $\mathrm{Ya}$ en el examen, Spitzer no ha cuidado tanto de devolver a la sucesión de estrofas el orden que Berceo les diera, sino el que les pudiera haber dado el arquetipo de "poeta medieval", tal como este sugestivo historiador lo concibe, que además hubiera cumplido aquí sin residuo el arquetipo de "composición medieval", tal como la filología moderna lo entiende. Posible sí que lo es, pero no probable en tal extremo. La crítica todavía tiene pues que pronunciarse sobre lo razonablemente seguro, lo probable y lo sólo posible en estas reordenaciones. Pero no es la intención de esta nota empezar la crítica proponiendo una nueva reordenación, ni menos regatear a Leo Spitzer nuestro aplauso, sino llamar la atención de nuestros colegas sobre su nota y reforzarla en general, ya que no en cada una de sus proposiciones, con la aducción de los tres intentos anteriores.

J. B. TREND

Cambridge.

\section{SANCHO SALDAÑA Y DON JUAN}

Característica común a los varios personajes que solemos llamar "Don Juan", y especialmente a los creados en el siglo xIx, es su desdén por las convenciones, reglas o disciplinas. El Sancho Saldaña de Espronceda es, a esta luz, un Don Juan que se mueve, sin cortapisas, tras sus apetencias.

Lo que le distingue esencialmente del protagonista de Zorrilla es el porqué de su desordenada conducta. A Tenorio lo domina su vitalidad desbordante, su ilusión del presente y del futuro próximo: la mujer a quien conquistar, el adversario a quien matar, el compañero a quien vencer en el juego. En Sancho Saldaña, por el contrario, violencias, engaños y muertes obedecen al deseo de acallar el pasado, de negarse a sí mismo, de olvidar:

... En la flor de su edad, alma árida como la arena y velado ya el rostro con la sombra de los sepulcros. En vano buscaba en las diversiones que su opulencia podía ofrecerle el alivio a sus penas que deseaba... Fastidiado de los placeres se entregó a toda clase de vicios para sepultar en el delirio del juego o de la embriaguez el tormento que le hostigaba.

Pero ni la ganancia le alegraba ni la pérdida le entristecía... mientras el vino... le entregaba más profundamente a todo el horror de sus pensamientos ${ }^{1}$.

1 José de Espronceda, Sancho Saldaña o el Castellano de Cuéllar, Madrid, 1870, vol. I, págs. 95 y sigs. (Primera edición, 1834.) 